Int.J. Hum. Soc. Dev. Res.

ISSN(P):2521-1439; ISSN(E):2523-4331

Volume 5, Number 1, 2021. 7-24

DOI: $10.30546 / 2523-4331.2021 .5 .1 .7$

\title{
SYSTEMIC RACISM IN A BROKEN SPECIAL EDUCATION SYSTEM
}

\author{
Andrew P. JOHNSON \\ Minnesota State University, Mankato, Minnesota USA
}

(C) The Author(s) 2021

\section{ABSTRACT}

The author argues that disability and race are both social constructs that should not be considered as disorders or deficits. Rather, these characteristics are merely differences among human beings, according to arbitrary standards set by those human beings. The medical model views a disability as disorder within the individual. The social model views disability as a restriction or disadvantage imposed on people with impairments that restrict them from fully participating in society. Disability is an area that intersects with race and culture because of inequitable expectations and diagnoses. There are a disproportionate number of students of color in the special education system. Descriptions are included for several specifically defined disabilities. The author suggests that inclusive classrooms are generally more effective than segregated instruction for students with special needs, if the inclusive classroom is taught by a knowledgeable and skilled teacher with class sizes that enable multilevel instruction.

\section{2021.All rights reserved.}

\section{ARTICLE HISTORY}

Received: 06/12/2020

Accepted:11/03/2021

Published online:30/04/2021

\section{KEYWORDS}

Racism, special education, inclusive classroom, social constructs 
A disability is not disorder or deficit; rather, it is merely a difference, a slight variation on the common theme of humanity. Disability is an area that intersects with race and culture because of inequitable expectations and diagnoses. This intersectionality is reflected in this paper.

\section{Disability as a Social Construct}

The Americans with Disabilities Act of 1990 (ADA) defines "disability" as a physical or mental impairment that substantially limits one or more major life activities. Major life activities include, but are not limited to, “care for one's self, performing manual tasks, seeing, hearing, eating, sleeping, walking, standing, lifting, bending, speaking, breathing, learning, reading, concentrating, thinking, communicating, and working." Like race, disability is a social construct based on the idea of a mythical norm or average (Shifrer, Muller, \& Callahan, 2016). In other words, human beings designed disability constructs to categorize other human beings based on their idea of what they think a normal human being is or is supposed to be.

\section{Models of Disabilities}

Models provide structures for perceiving the world and thinking about things that exist in that world. Two common disability models are the medical model and the social model.

\section{The medical model}

The medical model views disability as something that is 'wrong' with a person's body or mind. Here, the term "disorder" is often used in place of "disability." For example, in the Diagnostic and Statistical Manual of Mental Disorders (DSM-5), intellectual disabilities, autism spectrum disorder, attention-deficit/hyperactivity 
disorder, and specific learning disorder are all listed under "neurodevelopmental disorders" (American Psychiatric Association, 2013).

A disorder is the term used to indicate that some part of the body or mind is not functioning as it should. (i.e., There is an order that should be, and this thing is out of order.) Within this model, disabilities (or disorders) are viewed as deficits (Connor et al., 2019). Once diagnosed, treatments are prescribed to "fix" people with disabilities. Trained specialists administer the treatments in order to get the disabled person as close to "normal" as possible. Sadly, the medical model still dominates the special education system, a system in which students of color are disproportionately represented (Artiles, 2017; Connor, 2017; Fish, 2019; Shifrer et al., 2016; Voulgarides et al., 2017). This means that in our educational systems, a disproportionate number of students of color are seen as having a deficit.

\section{The social model}

In contrast to the medical model, the social model suggests that people with physical or other impairments are disabled by the way in which society acts (Fish, 2019). Here the disability lies, not within the individual, but on the social plane. With this model, a distinction is made between an impairment and a disability. An impairment is a condition or a part of the body or mind that is non-standard. For example, being blind, missing a limb, having a defective organ, or having a mental health condition are examples of impairments. A disability is the disadvantages or restrictions caused by a social group that ignores people with impairments thereby excluding them from full participation in the mainstream of that social group (Oliver, 1996). In other words, restrictions turn an impairment into a disability. No restriction, no disability. Restriction, disability.

In an educational setting, the following types of restrictions often turn impairments into disabilities: (a) class sizes that are too large, (b) poor quality of classroom instruction, (c) unqualified or underqualified teachers, (d) one-size-fits-all types of instruction or programs, (e) high stakes testing, (f) mismatches between students' culture and classroom curriculum, (g) culturally-biased assessment and 
instruction, (h) overly-harsh and unjust discipline, (i) teacher bias, and (j) generally treating students like products moving down a conveyer belt and not like people.

And these types of restrictions are much more likely to occur in schools serving poorer communities (Coutinho et al., 2002; U.S. Commission on Civil Rights, 2019), which (by the way) tend to include students of color at disproportionately higher rates (National Center for Education Statistics, 2019).

\section{Public Policy about Education and Disabilities}

In 1975, the US congress passed Public Law 94-142 - Education of All Handicapped Children Act. It was later amended and is now called Individuals with Disabilities Education Act of 2004 (IDEA). This law states that in order for schools to receive federal funds, they must provide free appropriate public education (FAPE) to all children with disabilities. Further, these students must receive special education services in the least restrictive environment (LRE). This means that to the greatest extent possible, students with special needs are to be educated in a general education classroom.

Figure 1 illustrates a continuum of services for special needs students from most to least restrictive. When reviewing the literature on disproportionality in special education, it becomes clear that both "appropriate" and "least restrictive" are subjective terms open to a variety of interpretations (Banks, 2017; Fish, 2019; Shifrer et al., 2016).

\section{Appropriate education}

Appropriate education means that instruction is directly related to each students' individual educational needs. Yet, instruction in special education settings is too often more standardized than individualized. That is, whole class instruction is used to implement standardized instructional programs and methods (Allington, 2013; Denton et al., 2003; Swanson, 2008; Swanson \& Vaughn, 2010). In terms of reading instruction, this can often have a deleterious effect (Allington, 2013; Bentum \& Aaron, 
2003). There are no magical one-size-fits all programs that work best for all students (Allington \& McGill-Franzen, 2017).

There are no super-secret special education strategies that only specially trained special education teachers can implement (Johnson, 2020). Instead, there are master teachers who have a variety of research-based tools in their teaching toolbox. And these tools should always be adopted and adapted to meet the unique needs of their students.

In other words, instruction should always be modified so that it is appropriate to meet the needs of the student and teaching situation. What might be appropriate for a $3^{\text {rd }}$ grade student with reading difficulties in Blackwater, Arizona, USA is most likely not appropriate for a $3^{\text {rd }}$ grade student with reading difficulties in Edina, Minnesota, USA.

\section{Figure 1.}

A continuum of services for students with special needs.

\begin{tabular}{|c|c|}
\hline $\begin{array}{c}\text { Most } \\
\text { restrictive }\end{array}$ & $\begin{array}{l}\text { Home or institution. Students are provided special education } \\
\text { services at home, or they reside in a treatment center in which } \\
\text { education is provided. }\end{array}$ \\
$\begin{array}{l}\text { - Special school. Students go to a special school designed to meet } \\
\text { their needs. }\end{array}$ \\
$\begin{array}{l}\text { - Full-time special classrooms. Students attend a special education } \\
\text { classroom full-time in a general education school. This allows } \\
\text { them contact with general education peers only during } \\
\text { nonacademic periods. } \\
\text { - Part-time in special classrooms. Students reside in a special } \\
\text { education classroom but are pulled for part of the day to attend } \\
\text { some general education classes (often non-academic classes such } \\
\text { as phy ed, art, music, etc.). }\end{array}$ \\
$\begin{array}{l}\text { Least } \\
\text { restrictive } \\
\text { gart-time in general education classrooms. Students reside in a } \\
\text { attend specific programs in a special education resource room. } \\
\text { - General Education with consultation. Students attend full time } \\
\text { in a general education classroom. Educational specialists consult } \\
\text { with the general education teacher to design instruction to meet } \\
\text { their needs. }\end{array}$ \\
\hline
\end{tabular}




\section{Least restrictive environment}

The least restrictive environment means that students with special learning needs should be in the general education classroom to the greatest extent possible. Special education should be a service, not a place. However, when compared to white students with the same disability label, African American students are more often educated in these highly restrictive segregated settings (Annamma et al., 2013; Banks, 2017; Blanchett, 2006; Connor, 2017; Shifrer et al., 2016; Zhang et al., 2014). And once students are placed in a segregated program, the chances that they will drop out of school, be arrested, be imprisoned and/or be unemployed after graduate all increase (Harry \& Klinger, 2014; Peterson \& Hittie, 2010; US Commission on Civil Rights, 2109). It is impossible to deny the fact that, whether intended or unintended, there are systems in place that disadvantage and restrict people of color. This is called systemic racism.

\section{Segregation and Inclusion}

Both segregated and inclusive classrooms are used to meet the learning needs of students identified as having a disability. Each of these is examined here.

\section{Segregated classrooms}

Segregated instruction is any instruction that occurs outside the general education classroom. (Note: We use the term "general education" classroom vs. "normal" classroom because a "normal" classroom infers that other classrooms are abnormal.) Segregated instruction could include full-time placement in a special education classroom (see Figure 1). It could also involve some sort of pull-out services where students are pulled out of the general education classroom for "specialized" instruction for part of the day or for single subject areas. This usually takes place in a special education resource room.

Diminished educational outcomes. At one time it was thought that smaller class sizes and additional adult resources found in a segregated special education 
classroom would enable teachers here to provide individualized instruction that would meet the special needs of each student. It was thought as well that this would lead to improved learning outcomes for these students. This may not be the case. It turns out that educational outcomes are more often diminished than enhanced in segregated settings (Allington \& McGill-Franzen, 2017; Artiles, 2017; Connor, 2017; Peterson \& Hittie, 2010). This is because students in segregated special education settings frequently do not receive the same quality of education as students in a general education classroom (Banks, 2017; Benner et al., 2011; Harry \& Klingner, 2014; Voulgarides \& Tefera, 2017). Also, the instruction here is often neither individualized nor appropriate (Allington \& McGill-Franzen, 2017; Zhang \& Katsiyannis, 2020).

Reading instruction. To illustrate, we will examine reading instruction. Within the special education system, approximately $85 \%$ of all the students receive some sort of "specialized" reading instruction (Sayeski, Budin, \& Bennett, 2015). The problem, however, is that students within this system rarely experience accelerated reading (Allington, 2011; Allington \& McGill-Franzen, 2017; Denton et al., 2003; Moody et al., 2000). This may be because they rarely get improved access to expert reading instruction (Allington, 2013, Harry \& Klingner, 2014). Students in special education resource rooms are taught by special education teachers, not reading specialists.

A special education teacher is not a reading specialist (Allington, 1994). The general orientation and the initial teacher preparation requirements are much different (Benner et al., 2011; Brownell et al., 2010; Brownell et al., 2005). These differences are reflected in the number and types of standards required by national accreditation organizations. Significantly fewer standards related to literacy instruction are required for preservice special education teachers than for preservice elementary education teachers (Council for Accreditation of Educator Preparation, 2018; Council for Exceptional Children, 2015). As well, the standards required by the Council for Exceptional Children's (CEC) for special education teachers focus on assessment, data collection, behavior management, and explicit, systematic instruction. There are no required CEC standards that focus specifically on developing students' ability to create meaning with print. 
As a result, the "specialized" reading instruction provided in special education settings is too often a one-size-fits-all program or method that relies primarily on direct instruction of low-level reading subskills (Denton et al., 2003; Eppley \& DudleyMarling, 2018; Klingner et al., 2010). While direct instruction is effective for learning low-level skills, it is extremely ineffective for developing high-level thinking, understanding complex concepts, and acquiring sophisticated skills (Allington, 2013).

And when direct instruction is overused to teach low-level reading sub-skills, students have few (if any) opportunities to read good books, engage in social interaction around good books or to develop complex thinking. In other words, if only low-level skills are taught in special education classrooms, only low-level learning occurs.

\section{Inclusive Classrooms}

In an inclusive classroom, instruction for students with special learning needs occurs within a general education classroom setting. Here, the teacher differentiates a common curriculum to meet the special learning needs of all students. Peterson and Hittie (2010) found that that, when compared to students in segregated settings, students in inclusive classrooms encounter (a) greater academic expectations, (b) a richer learning environment, (c) more effective teaching strategies, and (d) more exposure to modeling by more-able peers, all of which enhance learning. Also, social and emotional outcomes are better and there is greater achievement of IEP goals in inclusive classroom settings (Freeman \& Alkin, 2000).

Multilevel strategies. Simply putting students with special learning needs in a general education classroom does not make it an inclusive classroom. Also, just putting a special education teacher in the general education classroom as a co-teacher also does not make it an inclusive classroom. Instead, inclusive classrooms are those in which the classroom teachers have the knowledge and skills necessary to make inclusive teaching successful. They have a variety of multilevel strategies for differentiating a common curriculum. These could include some or all of the following: universal design for learning (UDL), contract learning, tiered assignments, workshop approaches for reading and writing, learning centers, goal setting, curriculum compacting, flexible grouping, 
workstations, jigsaw, project based learning, interest groups, shared reading, close reading, think-pair-share, and menus.

Effective inclusive classrooms. There are three elements necessary for effective inclusive classrooms: The first element is having an optimal number of students in the classroom. This number students varies; however, in general, pre-school through grade 1 should have a maximum of 12 to 15 students. Grades 2 and above, a maximum of 20 students.

Smaller class sizes enable the special learning needs of more students to be addressed within the inclusive general education classroom.

The second element necessary for effective inclusive classrooms is knowledgeable and skilled teachers. This means continued professional development opportunities for teachers. The goal here would be to enhance teachers' knowledge of and ability to use a variety of multilevel teaching strategies (see above).

The third element for effective inclusive classrooms is time to adequately plan, have conversations with other teachers, reflect, and revise. Some believe that effective teaching is simply a matter of buying the right program or product, taking it out of the box, reading the instructions, and then implementing it with fidelity. However, students are not standardized products. Communities, schools, classrooms, and teachers are not all the same. Every pedagogical strategy, program, method, or curriculum needs to be adopted and adapted to meet the unique learning needs of real-life students. This all takes time.

\section{Categorizing Persons with Disabilities}

There is a disproportionate number of students of color within the special education system. (Blanchet, 2006; US Commission on Civil Rights, 2019; Zhang \& Katsiyannis, 2020). Disproportionality is most present in the three high incidence categories: learning disabilities, emotional behavioral disorders, and intellectual 
disabilities (Artiles, 2017). These categories tend to have the most stigma attached to them (Fish, 2019). They are also the most subjective categories. Here, a teacher referral is a necessary part of the identification process. Teacher bias related to what is "normal" is one of the factors that leads to this disproportionality (Connor, 2017; Fish, 2019).

However, varying forms of bias and subjectivity exist in all parts of the process used to determine students' eligibility for special education services, including teacher referral, testing, and team meetings (Fish, 2019).

Within the larger educational system, there are disproportionate numbers of students of color involved in disciplinary actions, suspensions, school dropout rates, involvement with the legal system, and poverty (US Commission on Civil Rights, 2019). This disproportionality correlates with other aspects of society such as poverty, poor housing, low-level and low-paying jobs, unemployment, insufficient health care, single parent households, and rates of incarceration (Conner, 2017; Zhang \& Katsiyannis, 2020). These are just some of the variables that serve to disadvantage and restrict people of color. This is also an example of structural racism:

"We use the term structural racism to define the many factors that
contribute to and facilitate the maintenance of racial inequities in the
United States today. A structural racism analytical framework
identifies aspects of our history and culture that have allowed the
privileges associated with 'whiteness' and the disadvantages
associated with 'color' to endure and adapt over time. It points out the
ways in which public policies and institutional practices contribute to
inequitable racial outcomes. It lays out assumptions and stereotypes
that are embedded in our culture that, in effect, legitimize racial
disparities, and it illuminates the ways in which progress toward
racial equity is undermined" (Fulbright-Anderson et al., 2005, p.2).

\section{Specific Learning Disability}

As stated above, "disability" is a social construct. A "learning disability" is an educational construct. A learning disability is said to exist when there is a discrepancy between a student's expected ability and his or her achievement in one of seven areas: 
basic reading skill, reading comprehension, listening comprehension, oral expression, written expression, math calculation, and mathematics reasoning. Figure 2 includes the US Department of Education's definition for specific learning disability.

\section{Figure 2.}

IN GENERAL- The term 'specific learning disability' means a disorder in one or more of the basic psychological processes involved in understanding or in using language, spoken or written, which disorder may manifest itself in imperfect ability to listen, think, speak, read, write, spell, or do mathematical calculations.

SPECIFIC LEARNING DISABILITY. "Specific learning disability" means a condition within the pupil affecting learning, relative to potential, and is manifested by interference with the acquisition, organization, storage, retrieval, manipulation, or expression of information so that the pupil does not learn at an adequate rate when provided with the usual developmental opportunities and instruction from a regular school environment.

US Department of Education Definition of Specific Learning Disability

Source: Individuals with Disabilities Act, Sec. 300.8 (c) (10).

Using the medical model, The DSM-5 uses the term "disorder" vs. "disability" to define a specific learning disorder (See Figure 3):

\section{Figure 3.}

DSM-5 definition of specific learning disorder

Difficulties learning and using academic skills, as indicated by the presence of at least one of the following symptoms that have persisted for at least 6 months, despite the provision of interventions that target those difficulties:

1. Inaccurate or slow and effortful word reading.

2. Difficulty understand the meaning of what is read.

3. Difficulties with written expression.

5. Difficulties master number sense, number facts, or calculation.

6. Difficulties with mathematical reasoning.

Source: American Psychiatric Association, 2013.

However, learning is a natural human condition. Humans do it from the day they are born until they die. Thus, the term "learning disability" has meaning only in the 
artificial confines a school environment. However, humans eventually leave the schoolPetri dish and enter the real world.

Thus, schools must be very careful to not define any student's potential by giving him or her a label such as 'learning disability' when in fact, sometimes what is called a "learning disability" might actually be:

1. A learning-certain-kinds-of-things disability,

2. A learning-school-things disability,

3. A learning-things-you-don't-want-to-learn disability,

4. A learning-unnaturally disability,

5. A learning-not-as-fast-as-you-think-students-should-learn disability,

6. A teaching disability,

7. An educational-system disability,

8. A bad-things-happening-at-home disability, or

9. An over-crowded-classroom disability.

\section{Emotional or Behavioral Disorders}

An emotional or behavioral disorder (EBD) might be said to exist when one's emotions or behaviors get in the way of learning and participating in the learning environment. The US Department of Education's definition is in Figure 4.

This high incident disability category is subjected to teacher bias and cultural norms for the initial referral for special education placement. However, many behavior "disorders" can be undiagnosed mental health conditions, or they might be students' natural reactions to adverse conditions. The special education system seems to be designed to deal only with the ' $\mathrm{B}$ ' in $\mathrm{EBD}$, not the ' $\mathrm{E}$ '. That is, it addresses behaviors rather than the cause of behaviors. If teachers are emotionally present and attuned to the social, emotional, physical, and safety needs of all their students, many of the behaviors do not appear. Smaller class sizes enable teachers to better help students through difficult times. 


\section{Figure 4.}

US Department of Education Definition of Emotional or Behavioral Disorders

Emotional or behavioral disorders means an established pattern of one or more of the following emotional or behavioral responses: (a) withdrawal or anxiety, depression, problems with mood, or feelings of self-worth; (b) disordered thought processes with unusual behavior patterns and atypical communication styles; or (c) aggression, hyperactivity, or impulsivity.

The established pattern of emotional or behavioral responses must adversely affect educational or developmental performance, including intrapersonal, academic, vocational, or social skills; be significantly different from appropriate age, cultural, or ethnic norms; and be more than temporary, expected responses to stressful events in the environment. The emotional or behavioral responses must be consistently exhibited in at least three different settings, two of which must be educational settings, and one other setting in either the home, child care, or community. The responses must not be primarily the result of intellectual, sensory, or acute or chronic physical health conditions.

Source: Individuals with Disabilities Act, Sec. 300.8 (c) (4).

\section{Intellectual Disability}

As stated above, a disability is not a deficit or deficiency; rather, it is a variation on the human theme. The official definitions for an intellectual disability are in Figures 5 and 6 below.

\section{Figure 5.}

US Department of Education Definition of Intellectual Disability

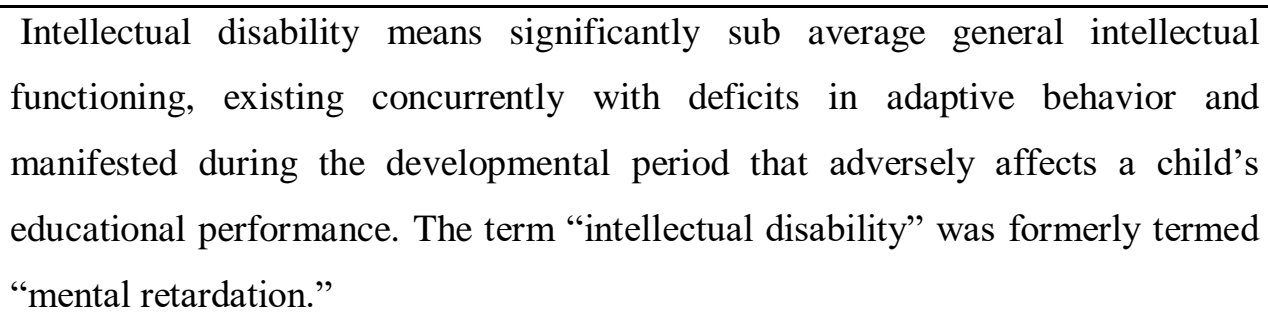
functioning, existing concurrently with deficits in adaptive behavior and manifested during the developmental period that adversely affects a child's educational performance. The term "intellectual disability" was formerly termed "mental retardation."

Source: Individuals with Disabilities Act, Sec. 300.9 (c) (6). 


\section{Figure 6.}

DSM-5 Definition of Intellectual Disability

Intellectual disability (intellectual developmental disorder) is a disorder with onset during the developmental period that includes both intellectual and adaptive functioning deficits in conceptual, social, and practice domains.

Source: American Psychiatric Association, 2013.

\section{Attention Deficit/Hyperactivity Disorder}

Students with Attention Deficit/Hyperactivity Disorder (ADHD) have a hard time concentrating or focusing. The U.S. Department of Education defers to the DSM-5 when offering a medical-based definition. It is "a persistent pattern of inattention and/or hyperactivity-impulsivity that interferes with function or development" (American Psychiatric Association, 2013, p. 31). The "symptoms" are:

"Inattention: Six or more symptoms of inattention for children up to age 16 years, or five or more for adolescents age 17 years and older and adults; symptoms of inattention have been present for at least 6 months, and they are inappropriate for developmental level:

- Often fails to give close attention to details or makes careless mistakes in schoolwork, at work, or with other activities.

- Often has trouble holding attention on tasks or play activities.

- Often does not seem to listen when spoken to directly.

- Often does not follow through on instructions and fails to finish schoolwork, chores, or duties in the workplace (e.g., loses focus, side-tracked).

- Often has trouble organizing tasks and activities.

- Often avoids, dislikes, or is reluctant to do tasks that require mental effort over a long period of time (such as schoolwork or homework).

- Often loses things necessary for tasks and activities (e.g. school materials, pencils, books, tools, wallets, keys, paperwork, eyeglasses, mobile telephones).

- Is often easily distracted 
- Is often forgetful in daily activities" (American Psychiatric Association, 2013, p. 32).

"Hyperactivity and Impulsivity: Six or more symptoms of hyperactivityimpulsivity for children up to age 16 years, or five or more for adolescents age 17 years and older and adults; symptoms of hyperactivity-impulsivity have been present for at least 6 months to an extent that is disruptive and inappropriate for the person's developmental level:

- Often fidgets with or taps hands or feet, or squirms in seat.

- Often leaves seat in situations when remaining seated is expected.

- Often runs about or climbs in situations where it is not appropriate (adolescents or adults may be limited to feeling restless).

- Often unable to play or take part in leisure activities quietly.

Is often "on the go" acting as if "driven by a motor".

- Often talks excessively.

- Often blurts out an answer before a question has been completed.

- Often has trouble waiting their turn.

- Often interrupts or intrudes on others (e.g., butts into conversations or games)" (American Psychiatric Association, 2013, pp. 32-33).

Two things to consider here. First, these are all based on a subjective determination of "normal". This serves to reinforce parochial conceptions of normality and abnormality where teacher bias plays a large part in the initial referral. Second, these "symptoms" are also common effects of poor nutrition, poverty, and chronic and acute stress all of which disproportionately affect minority students.

\section{Other Disability Categories}

In this article, four disability categories were briefly described. The U.S. Department of Education recognizes 13 disability categories:

- Autism,

- Deaf-blindness,

- Deafness, 
- Emotional disturbance,

- Hearing impairment,

- Intellectual disability,

- Multiple disabilities,

- Orthopedic impairment,

- Other health impairment (including ADHD),

- Specific learning disability,

- Speech or language impairment,

- Traumatic brain injury, and

- Visual impairment (including blindness).

\section{Big Ideas in This Paper}

1. Disability and race are both social constructs.

2. A disability is not disorder or deficit; rather, it is merely a difference.

3. The medical model views a disability as disorder within the individual.

4. The social model views disability as a restriction or disadvantage imposed on people with impairments that restrict them from fully participating in society.

5. Inclusive classrooms are generally more effective than segregated instruction for students with special needs if taught by a knowledgeable and skilled teacher with class sizes that enable multilevel instruction.

6. There are a disproportionate number of students of color in the special education system.

\section{Disclosure statement}

No potential conflict of interest was reported by the author.

\section{Contact Information.}

www.teaching-reading.com

https://orcid.org/0000-0002-3843-4942 


\section{References and notes:}

Allington, R. L. \& McGill-Franzen, A., (2017). Comprehension difficulties and struggling readers. Pp 271292. In S. Israel (Ed.). Handbook of research on reading comprehension, (2nd ed.). New York, NY: The Guilford Press.

Allington, R. L. (1994). What's so special about special programs for children who find learning to read difficult? Journal of Reading Behavior, 26(1), 95-115.

Allington, R. L. (2011). Research on reading/learning disability interventions. In S.J. Samuels and A. E. Farstrup's (Eds.) What research has to say about reading instruction, (4th ed.). Newark, DE: International Reading Association.

Allington, R. L. (2013). What really matters when working with struggling readers. The Reading Teachers, 66, 520-530. https://doi.org/10.1002/TRTR.1154

American Psychiatric Association. (2013). Diagnostic and Statistical Manual of Mental Disorders (5th ed.). Arlington, VA: American Psychiatric Association.

Americans with Disabilities Act of 1990, Pub. L. No. 101-336, 104 Stat. 328 (1990). Retrieved March 11, 2021 from https://www.ada.gov/cguide.htm\#anchor62335.

Annamma, S. A., Connor, D., \& Feri, B. (2013). Dis/ability critical race studies (DisCrit): Theorizing at the intersections of race and dis/ability. Race, Ethnicity and Education, 16, 1-3. DOI: $10.1080 / 13613324.2012 .73511$

Artiles, A. (2017). Untangling the racialization of disabilities: An intersectional critique across disability models. Du Bois Review, 10, 329-347.

Banks, J. (2017).”These people are never going to stop labeling me": Educational experience of African American male students labeled with learning disabilities. Equity and Excellence in Education, 50, 96-97.

Benner, S., Bell, S., \& Broemmel, A. (2011). Teacher education and reading disabilities. 68-79. In A. McGill-Franzen \& R. Allington (Eds.). Handbook of reading disability research. New York, NY: Routledge.

Bentum, K., \& Aaron, P. (2003) Does reading instruction in learning disability resource rooms really Work?: A longitudinal study. Reading Psychology, 24, 361-382 DOI: $10.1080 / 02702710390227387$

Blanchett, W. (2006). Disproportionate representation of African American students in special education: Acknowledging the role of White privilege and racism. Educational Research, 35, 24-28.

Brownell, M. Ross, D., Colón, E., \& McCallum, C. (2005). Critical features of special education teacher preparation: A comparison with general teacher education. The Journal of Special Education, 38, 242-252.

Brownell, M., Klingner, J., Leko, M., \& Galman, S (2010). Differences in beginning special education teachers: the influence of personal attributes, preparation, and school environment on classroom reading practices. Learning Disability Quarterly, 33, 75-92

Conner, D. (2017). Who is responsible for racialized practices evident within (special) education and what can be done to change them? Theory into Practice, 56, 226-233.

Connor, D., Cavendish, W., Gonzalez, T., \& Jean-Pierce, P. (2019). Is a bridge every possible over troubled waters? The field of special education negates the overrepresentation of minority students: A DisCrit analysis. Race, Ethnicity and Education, 22, 723-745.

Council for Exceptional Children. (2015). Professional Preparation Standards. Arlington, VA: Council for Exceptional Children. Retrieved March 11, 2021 from https://exceptionalchildren.org/standards.

Council for the Accreditation of Educator Preparation. (2018). CAEP 2018 K-6 elementary teacher preparation standards: Initial licensure programs. Washington, DC: CAEP. http://caepnet.org/ /media/Files/caep/standards/2018-caep-k-6-elementary-teacherprepara.pdf?la=en

Coutinho, M. J. Oswal, D. P., \& Best, A. M. (2002). The influence of sociodemographics on the disproportionate identification of minority students as having learning disabilities. Remedial and Special Education, 23, 49-59.

Denton, C. A., Vaugh, S., \& Fletcher, J. M. (2003). Braining research-based practice in reading intervention to scale. Learning Disabilities Research and Practice, 18(3), 201-211.

Eppley, K., \& Dudley-Marling, C. (2018). Does direction instruction work?: A critical assessment of direct instruction research and its theoretical perspective. Journal of Curriculum and Pedagogy, 14, 1-20. Doi.org/10.1080/1550570.2018.143821 
Fish, R.E. (2019). Standing out and soring in: Exploring the role of racial composition in racial disparities in special education. American Education Research Journal, 56, 2578-2608.

Freeman, S., \& Alkin, M. (2000). Academic and social attainments of children with mental retardation in general education and special education settings. Remedial and Special Education, 21(1), 318.

Fulbright-Anderson, K., Lawrence, K., Sutton, S., Susi, G., \& Kubi, A. (2005). Structural racism and youth development: Issues, challenges, and implication. Aspen Institute Roundtable on Community Change and Advisors to the Project on Structural Racism and Community Revitalization.

Harry, B., \& Klinger, J. (2014). Why are so many minority students in special education? Understanding race and disability in schools (2nd ed.). New York, NY: Teachers College Press.

Individuals with Disabilities Education Act, 20 U.S.C. § 1400. (2004).

Johnson, A. (2020). Designing meaning-based interventions for reading. New York, NY: Guildford Press.

Klingner, J., Urbach, J., Golos, D., Brownell, M., \& Menon, S. (2010). Teaching reading in the 21st century: A glimpse at how special education teachers promote reading comprehension. Learning Disability Quarterly, 33, 59-74.

Kohli, R., Pizarro, M., \& Nevarez, A. (2019). The "new racism" of K-12 schools: Centering critical research on racism. Review of Research in Education, 41, 182-202.

Moody, S., Vaugh, S., \& Hughes, M. (2000). Reading instruction in the resource room: Set up for failure. Exceptional Children, 66(3), 305-316.

National Center for Education Statistics. (2019). Status and Trends in the Education of Racial and Ethnic Groups 2018. Washington, D.C.: U.S. Department of Education.

Oliver, M. (1996). Understanding disability: from theory to practice. New York: St. Martin's Press; 1996.

Peterson, M. \& Hittie, M. (2010). Inclusive teaching: The journey towards effective schools for all learners. Columbus, OH: Merrill.

Sayeski, K., Budin, S., \& Bennett, K. (2015). Promising practices in the preparation of special educators to provide reading instruction. Intervention in School and Clinic, 51, 82-89.

Shifrer, D., Muller, C., \& Callahan, R. (2016). Disproportionality and learning disabilities: Parsing apart race, socioeconomic status, and language. Journal of Learning Disabilities, 44, 246-257.

Swanson, E. (2008) Observing reading instruction for students with learning disabilities: A synthesis. Learning Disabilities, 31, 115-133.

Swanson, E., \& Vaughn, S. (2010). An observation study of reading instruction provided to elementary students with learning disabilities in the resource room. Psychology in the Schools, 47, 481492. DOI: $10.1002 /$ pits. 20484

U.S. Commission on Civil Rights. (2019). Beyond Suspensions: Examining School Discipline Policies and Connections to the School-to-Prison Pipeline for Students of Color with Disabilities. https://www.usccr.gov/pubs/2019/07-23-Beyond-Suspensions.pdf

Voulgarides, C. K \& Tefera, A. (2017). Reframing the racialization of disability in policy. Theory into practice, 56, 161-168.

Voulgarides, C. K., Fergus, E., \& Torius, K.A.K. (2017). Prsuing equity: Disproportionality in special education and the reframing of technical solutions or address systematic inequities. Review of Research in Education, 41, 61-87.

Zhang, D., \& Katsiyannis, A. (2020). Minority representation ins special education: A persistent challenge. Remedial and Special education, 23, 180-187.

Zhang, D., Katsiyannis, A., Ju, S., \& Roberts, E. (2014). Minority representation in special education: 5 year trends. Journal of Child and Family Studies, 23, 118-127. 